
\title{
Research Suare \\ Construction of a Mutant Bacillus Subtilis Strain for High Purity Poly-y-Glutamic Acid Production
}

\section{Linlin $\mathrm{He}$}

Tianjin University

Lu Liu

Tianjin University

Rui Ban ( $\boldsymbol{D}$ banrui1196@163.com )

Tianjin University https://orcid.org/0000-0001-6425-1587

\section{Research Article}

Keywords: Bacillus subtilis, poly-y-glutamic acid, extracellular proteins, gene knockout, fla-che operon, yrpD

Posted Date: January 7th, 2022

DOI: https://doi.org/10.21203/rs.3.rs-1206016/v1

License: @ (i) This work is licensed under a Creative Commons Attribution 4.0 International License. Read Full License 


\section{Abstract \\ Purpose}

To construct a Bacillus subtilis strain for improved purity of poly-y-glutamic acid.

\section{Results}

The construction of strain $\mathrm{GH} 16$ was achieved by knocking out five extracellular protein genes and an operon from Bacillus subtilis G423. Then we analyzed the protein content in the Y-PGA produced by the resultant strain GH16/pHPG which decreased by $6.08 \%$. Subsequently the fla-che operon, $P B S X$ and the $y r p D, y w o F$ and $y c l Q$ genes were knocked out successively and the mutant strain $\mathrm{GH} 17, \mathrm{GH} 18$, and $\mathrm{GH} 19$ was obtained. Ultimately, the protein content was reduced by $43.9 \%$. In addition, the polysaccharide content in the $\mathrm{Y}$-PGA was decreased from $2.21-1.93 \%$ due to the epsA-O operon was knocked.

\section{Conclusion}

Y-PGA has potential applications as a drug carrier, sustained-releasing agent and medical composite in medicine. To our knowledge, this is the first report of engineered Bacillus subtilis strains which can produce $\gamma$-PGA with a purity higher than $97 \%$. Our results confirmed that this upstream strategy significantly enhanced specific protein purity by the removal of extracellular protein genes in Bacillus subtilis, and it is promising in other protein purification.

\section{Introduction}

Poly-y-glutamic acid ( $\gamma-P G A)$, a polypeptide-type biopolymer, is formed by the polymerization of $D$ glutamate and L-glutamate through the $\gamma$-amide bond (Ashiuchi $M$ et al. 2004). $y$-PGA has a broad application prospects in medicine, food, cosmetics, agriculture and environmental protection due to the property of water soluble, biodegradable, nontoxic, water-retentive and biocompatible [Buescher JM and Margaritis A. 2007; Shih IL and Van YT. 2001; Yu X et al. 2011;Park SJ et al.2019). Therefore, the immunogenic impurities such as proteins and polysaccharides should be removed as much as possible in order to avoid possible hypersensitivity.

At present, $\mathrm{Y}$-PGA is mainly produced by bacillus species, among which Bacillus subtilis is a commonly used strain (Min JH et al. 2019). $y$-PGA is the extracellular product of bacteria and coexists in fermentation broth with other biological polymer such as proteins and polysaccharides secreted by cells. General methods for extracting Y-PGA from fermentation broth include organic solvent precipitation, salting out or membrane filtration (Goto A and Kunioka M 1992; Manocha B and Margaritis A 2010; Kumar R and Pal P 2015). However, because of the similarly macromolecular properties, none of these methods can completely separate proteins and polysaccharides from $\mathrm{y}$-PGA. As a result, there is a certain 
amount of proteins and polysaccharides in the final product, and the problem seems to be difficult to solve just with downstream technology. Currently, the purity of commercially available y-PGA for cosmetics is between $92 \%$ and $95 \%$, but the content of mixed protein and polysaccharide is not indicated.

Bacillus subtilis have the capability to secrete more than 300 extracellular proteins (Tjalsma $\mathrm{H}$ et al. 2000; Tjalsma $\mathrm{H}$ et al. 2004), and under different fermentation conditions, it shows significant differences in the types and quantities of extracellular proteins (Yamane $\mathrm{K}$ et al. 2000). It is generally accepted that proteins such as TasA, Hag, YlqB, XlyA, XkdM, XkdG, YolA, yclQ, Csn, WprA, LipA, FlgK, Epr, Bpr and YncM are abundant extracellular proteins in the fermentation broth (Tjalsma $\mathrm{H}$ et al. 2004; Yamane $\mathrm{K}$ et al. 2000). However, with certain y-PGA producing strains and in the background of $\mathrm{y}$-PGA synthesis, these high secretion extracellular proteins have not been determined. Therefore, it is meaningful and timely to improve the purity of $\mathrm{Y}$-PGA by removing extracellular proteins which are abundant in the fermentation broth. On other hand, exopolysaccharide(EPS) is also a kind of impurity which affect the quality of $\mathrm{Y}$-PGA. The EPS mainly refers to the polysaccharides that make up the biofilm of Bacillus subtilis (Nagorska K 2010). EPS is a complex polysaccharide with a molecular weight between 500-2000 kDa (Sutherland I 2001;Marvasi M et al. 2010) and its synthesis is related to the epsA-O operon which is approximately 15 $\mathrm{kb}$ in length and contains 15 genes encoding a variety of glycosyltransferases (Guttenplan SB 2010). It is difficult to remove EPS by purification technology, so removing the EPS by gene knockout may increase the $\mathrm{Y}$-PGA purity.

In this work, we will attempt to reduce the extracellular proteins or polysaccharides by knocking out some genes involved in the synthesis of extracellular proteins or polysaccharides from Bacillus subtilis. The strains construction process was shown in figure 1. Also, the effects of the deletion of these genes on cell growth, $y$-PGA synthesis and y-PGA purity will be investigated. Finally, we provide perspectives for the Bacillus subtilis strains as cell factories to synthesis certain protein with high purity, and the results obtained here may be useful for the industrial production of $\mathrm{Y}$-PGA.

\section{Materials And Methods}

\section{Strains, plasmids and growth conditions}

All the strains and plasmids used in this work were listed in Supplementary Table 1.

For $\mathrm{Y}$-PGA production or extracellular proteins analysis, B. subtilis were cultured at $37^{\circ} \mathrm{C}, 225 \mathrm{rpm}$ for $40 \mathrm{~h}$ in fermentation medium: $5 \%(\mathrm{w} / \mathrm{v}$, the same below) glucose, $4.5 \%$ sodium glutamate, $0.5 \%$ yeast extract, $0.05 \% \mathrm{MgSO} 4 \cdot 7 \mathrm{H} 2 \mathrm{O}, 0.002 \% \mathrm{ZgSO} \cdot 7 \mathrm{H} 2 \mathrm{O}, 0.002 \% \mathrm{MnSO} 4,0.26 \% \mathrm{KH} 2 \mathrm{PO} 4,0.54 \% \mathrm{~K} 2 \mathrm{HPO} 4$. The optical density (OD) of the fermentation broth was measured at $600 \mathrm{~nm}$ using a spectrophotometer (Bioquest CE2502, UK). Luria-Bertani (LB) medium was used for the general cultivation of Bacillus subtilis. Antibiotics were used at the following concentrations as needed: $6 \mu \mathrm{g} / \mathrm{ml}$ chloramphenicol, 15 $\mu \mathrm{g} / \mathrm{ml}$ neomycin. 


\section{Knockout of gene}

The manipulation of marker-free gene deletion was conducted according to standard procedures (Liu S 2008). Competent cells were prepared by a previously described method (Anagnostopoulos $C$ and Spizizen J 1961). The Specific genetic technique used in this study was as described previously (Zhu $\mathrm{H}$ et al. 2015). All fragments were amplified using the genome of B. subtilis TD01m as a template. The oligonucleotide primers used in this study were listed in Supplementary Table 2.

Briefly, with ywof gene as an example, the procedure for deleting the ywof gene was conducted as follows: Firstly, the $1.2 \mathrm{~kb}$ upstream homologous fragment $(\mathrm{U})$ of ywof gene was amplified by PCR with the primer ywoUP1/ywoUP2, and the $0.75 \mathrm{~kb}$ internal homologous fragment (D) was amplified using the primer ywoDN1/ywoDN2. Secondly the $2.1 \mathrm{~kb}$ selective marker cassette (CR) was amplified with primer ywoCR1/ywoCR2, and the $1.0 \mathrm{~kb}$ downstream homologous fragment $(\mathrm{G})$ was amplified with primers ywoG1/ywoG2. Thirdly the four fragments were then ligated in the order U-D-CR-G by splicing by overlapped extension PCR (SOE-PCR) with primers ywoUP1/ywoG2 and the resultant fragment UDCRG was used to transform the competent cells of Bacillus subtilis. The resistant colony of chloramphenicol was selected and incubated in LB medium for $4 \mathrm{~h}$, during which the intragenomic single-crossover event caused the CRG fragment to be ejected. Finally, the ywof deficient strain could be selected based on neomycin resistance.

In special cases, the available homology arms would be short inevitably if the length of target gene sequence was short $(<600 \mathrm{bp})$, which would cause the results in a low rate of homologous recombination. At this point, the target gene sequence should be replaced with the erythromycin-resistant gene emr and then emr gene was knocked out using the marker-free deletion method. Finally, the purpose of knocking out the target gene was achieved.

\section{Analysis of $\mathrm{Y}-\mathrm{PGA}$ in fermentation broth}

The concentration of $\mathrm{Y}$-PGA in the fermentation broth were measured using a high performance liquid chromatography (Agilent1260, USA) with an aquagel column (Agilent PL aquagel-OH 60, $8 \mu \mathrm{m}$ ) and a refractive index detector (Agilent $1260 \mathrm{G1362A}$, USA). Sodium nitrate solution (100 mmol/L) was used as the mobile phase with a flow rate of $1.0 \mathrm{ml} / \mathrm{min}$ at $30^{\circ} \mathrm{C}$. The fermentation broth was diluted 60 times with deionized water as a sample for analysis and injection volume was $50 \mu \mathrm{l}$. For quantitative analysis of the $\mathrm{Y}$-PGA content, a series of concentrations of $\mathrm{\gamma}$-PGA standard solution $(0.25,0.50,0.75,1.00,1.25$ $\mathrm{g} / \mathrm{L}$ ) were analyzed with above conditions. Then the obtained peak area and sample concentration were linearly fitted to obtain a linear equation. Based on this linear equation, the concentrations of $\mathrm{Y}-\mathrm{PGA}$ in the fermentation broth was calculated according to the following formula:

$\mathrm{C}(\mathrm{g} / \mathrm{L})=(0.1945 \mathrm{~A}+0.0879) \times 60$, where $\mathrm{A}$ was the peak area $(\times 10-5)$ of $\mathrm{Y}-\mathrm{PGA}$; the value 0.1945 was slope of the linear equation; the value 0.0879 was intercept of the linear equation; the value 60 was dilution factor. $r 2=0.998$. 


\section{Preparation of $\mathrm{Y}-\mathrm{PGA}$ product}

The ethanol precipitation was used to extract y-PGA from the fermentation broth as previously described (Goto A and Kunioka M 1992). To remove small molecule impurities, the crude $Y$-PGA product was transferred to a dialysis bag (YA1073, Solarbio) and dialyzed for $20 \mathrm{~h}$ using ultrapure water as dialysate. Then the retention solution was dried in vacuo to obtain a $y$-PGA product.

\section{Analysis of protein in Y-PGA product}

The aqueous solution of $\mathrm{Y}$-PGA product with a concentration of $5 \mathrm{mg} / \mathrm{mL}$ was prepared as a sample to be tested. The protein content in the sample was measured using a Bradford protein concentration assay kit (PC0015, Solarbio). For quantitative analysis of the protein content, a series of concentrations of bovine serum albumin (BSA) standard solution $(0.04,0.08,0.12,0.16,0.20 \mathrm{mg} / \mathrm{mL})$ were analyzed. Then the obtained OD595 value and sample concentration were linearly fitted to obtain a linear equation. The protein content in $\mathrm{Y}$-PGA product was calculated according to the following formula:

$Y(w / w)=(0.3039 A-0.0087) / 5 \times 100 \%$, where $A$ was the OD595 value of the sample; the value 0.3039 was slope of the linear equation; the value -0.0087 was intercept of the linear equation; the value 5 was conversion factor related to sample concentrition. $r 2=0.993$.

\section{Analysis of polysaccharide in Y-PGA product}

The aqueous solution of $y-P G A$ product with a concentration of $5 \mathrm{mg} / \mathrm{mL}$ was prepared as a sample to be tested. The polysaccharide content was measured by the phenol-sulfuric acid method (Yu KH et al. 2005). For quantitative analysis of the polysaccharide content, a series of concentrations of glucose standard solution $(0.01,0.02,0.04,0.06,0.08 \mathrm{mg} / \mathrm{mL})$ were analyzed. Then the obtained OD490 value and sample concentration were linearly fitted to obtain a linear equation. Considering the addition of water molecules when hydrolyzing polysaccharides, the polysaccharide content in $\mathrm{Y}$-PGA was calculated according to the following formula:

$\mathrm{Z}(\mathrm{w} / \mathrm{w})=(0.0685 \mathrm{~A}+0.0007) / 5 \times 0.9 \times 100 \%$, where $\mathrm{A}$ was the OD490 value of the sample; the value 0.0685 was slope of the linear equation; the value 0.0007 was intercept of the linear equation; the value 5 was conversion factor related to sample concentration; the value 0.9 was conversion factor related to addition of water molecules. $r 2=0.999$.

\section{SDS-PAGE analysis of extracellular protein extracts}

Strains without plasmid were cultured for $40 \mathrm{~h}$. Extracellular proteins in the fermentation broth was extracted by ethanol precipitation. The pellet was dissolved with deionized water and was concentrated for forty times. The $20 \mu \mathrm{L}$ protein solution was mixed with an equal volume of $2 x$ loading buffer (P1019, 
Solarbio) and then was boiled for $12 \mathrm{~min}$. The $15 \mu \mathrm{L}$ mixed sample was loaded and subjected to sodium dodecyl sulfate-polyacrylamide gel electrophoresis(SDS-PAGE).

\section{Mass Spectrometry analysis of extracellular proteins}

The extracellular protein extract was initially purified by SDS-PAGE. Cutting gel and in-gel digestion were performed by a previously described method (Estacio W et al. 1998). Then the samples were analyzed by ultra performance liquid chromatograph Easy nLC 1200 (Thermo Scientific, USA) with an Easy-spray column $(\mathrm{C} 18,2 \mu \mathrm{m} \times 75 \mu \mathrm{m} \times 15 \mathrm{~cm})$ and Q-Exactive HF mass spectrometer (Thermo Scientific, USA). The solution A ( $0.1 \%$ formic acid / $\mathrm{H} 2 \mathrm{O})$ and solution $\mathrm{B}(0.1 \%$ formic acid / acetonitrile) were used as the mobile phase with a flow rate of $600 \mathrm{~nL} \mathrm{min-1}$ and the gradient elution was performed as Supplementary Table 4. The important mass spectrometry parameters were set as follows: ion spray voltage: $2.3 \mathrm{kV}$; capillary temperature: $250^{\circ} \mathrm{C}$; analysis mode: Full MS/dd-MS2. The software Mascot 2.5.1 (Matrix Science, USA) was used to analyse the mass spectral data based on the Uniprot [Bacillus subtilis (strain 168)] database.

\section{Results And Discussion}

\section{The effect Deletion of several extracellular protein genes and its effects}

B.subtilis G423, a host of the $\mathrm{\gamma}$-PGA synthase expression plasmid, its genes encoding neutral metalloprotease NprE (EC: 3.4.24.28), alkaline serine protease AprE (EC: 3.4.21.62), xylanase XynA (EC:3.2.1.8), chitosanase Csn (EC:3.2.1.132) and hypothetical proteins (YolA, YolB and YncM) had been deleted in our previous work. Based on the physiological functions and 2D-PAGE of the extracellular proteins (Tjalsma H et al. 2004; Yamane $\mathrm{K}$ et al. 2000), it could be confirmed that the biofilm constituent proteins TasA and YqxM, lipase LipA (EC: 3.1.1.3), serine proteases Epr (EC: 3.4.21.-), bacillus peptidase Bpr (EC: 3.4.21.-) and the unknown proteins YlqB and YweA were the retained extracellular proteins with high content in B.subtilis G423 broth. Therefore, it is necessary that the genes encoding the above proteins should be deleted in G423 strain to prevent their synthesis.

As a result, the tas A-yqxM operon, lip, epr, bpr, ylqB and yweA genes was successively knocked out from G423 strain and the deficient strain GH16 was obtained. After introducing the $\mathrm{\gamma}$-PGA expression plasmid pHPG into the GH16 strain, shake flask fermentation of G423/pHPG and GH16/pHPG showed that the deletion of these genes had no significant effect on cell growth and $y$-PGA synthesis (Fig. 2A). Also, the conversion rate, ratio of $\mathrm{Y}-\mathrm{PGA}$ production to glucose and glutamate consumption, only changed slightly (Fig. 3A and Table 1). However, the protein content in Y-PGA produced by G423/pHPG and GH16/pHPG was $1.48 \%$ and $1.39 \%$ respectively, and the decline was $6.08 \%$ (Fig. 3B and Table 1 ). SDS-PAGE analysis of the extracellular proteins extracted from the fermentation broth of G423 strain and GH16 strain showed no significant difference in the protein bands (Fig. 4). Consequently, TasA, YqxM, Epr, Bpr, LipA, 
YlqB and YweA were not the major extracellular proteins and had a slight effect on improving the purity of $\mathrm{Y}$-PGA with the deletion of the above genes.

Table 1

Comparison of y-PGA fermentation results between G423/pHPG and mutant strains

\begin{tabular}{|llllll|}
\hline Strains & $\begin{array}{l}\text { Y-PGA } \\
\text { yield }\end{array}$ & $\begin{array}{l}\text { Protein } \\
\text { content } \\
\left(\mathbf{g} \cdot \mathrm{L}^{-1}\right)\end{array}$ & $\begin{array}{l}\text { Polysaccharide } \\
\text { content } \\
(\%)\end{array}$ & $\begin{array}{l}\text { conversion } \\
\text { rate } \\
\text { (glucose- } \\
\text { based) } \\
(\%)\end{array}$ & $\begin{array}{l}\text { conversion rate } \\
\text { (glutamic- } \\
\text { based) } \\
(\%)\end{array}$ \\
\hline G423/pHPG & $24.67 \pm 0.89$ & $1.48 \pm 0.07$ & $2.21 \pm 0.09$ & $74.02 \pm 1.02$ & $95.25 \pm 0.57$ \\
\hline GH16/pHPG & $24.52 \pm 1.01$ & $1.39 \pm 0.08$ & NA & $72.33 \pm 1.66$ & $94.67 \pm 1.21$ \\
\hline GH17/pHPG & $25.51 \pm 0.85$ & $1.24 \pm 0.07$ & NA & $80.22 \pm 0.98$ & $97.00 \pm 0.89$ \\
\hline GH18/pHPG & $24.82 \pm 0.94$ & $1.07 \pm 0.1$ & $2.17 \pm 0.14$ & $77.56 \pm 0.79$ & $96.58 \pm 0.43$ \\
\hline GH19/pHPG & $25.22 \pm 0.73$ & $0.83 \pm 0.05$ & NA & $78.57 \pm 1.32$ & $96.63 \pm 0.93$ \\
\hline GH21/pHPG & $22.40 \pm 0.38$ & NA & $1.93 \pm 0.11$ & $74.42 \pm 0.65$ & $96.55 \pm 1.13$ \\
\hline
\end{tabular}

\section{Effects of deleting the fla-che operon}

The fla-che operon of B. subtilis, consisting of 31 coding sequences, encodes hook-basal body (HBB), RNA polymerase recognition factor SigD and other proteins related to chemotaxis (Estacio W et al. 1998). In addition, the flgM operon, hag gene and yvyC-fliT operon are responsible for synthesizing the filament proteins and junction proteins(Estacio $W$ et al. 1998). The above flagellar proteins are present in the fermentation broth of Bacillus subtilis with a high content (Tjalsma H et al. 2004; Yamane $\mathrm{K}$ et al. 2000), which may affect the purity of the $\mathrm{Y}$-PGA product. Coincidentally, the expression of flgM operon, hag gene and yvyC-fliT operon are all dependent on the presence of SigD factor (Mukherjee S and Kearns DB 2014). Therefore, as long as the fla-che operon was deleted, these genes encoding flagellar proteins will be silenced.

The flagellar deficient strain $\mathrm{GH} 17$ was constructed by deleting the front 30 genes of the fla-che operon in $\mathrm{GH} 16$ strain and terminal ylxL gene was retained. As a result, the deletion of fla-che operon reduced the protein content in $\mathrm{Y}$-PGA to $1.24 \%$ and promoted the synthesis of $\mathrm{Y}$-PGA (Table 1 and Fig. $3 \mathrm{~A}$ ). Compared to the $\mathrm{GH} 16 / \mathrm{pHPG}$ strain, the decrease rate of protein content was $10.8 \%$ (Fig. 3B). It indicated that the deletion of fla-che operon can help to reduce the synthesis of extracellular proteins and improve the purity of $y$-PGA product. 
The biomass of GH17 strain in shaker fermentation was slightly higher than that of the GH16 strain (Fig. $2 A)$. The defect of flagella was likely to reduce the metabolic load of cells so that lead to a higher biomass. This view could also be supported by the fact that the glucose conversion rate based on $\mathrm{y}-\mathrm{PGA}$ production had increased from $72.33-80.22 \%$ (Table 1). At the same time, the conversion rate of glutamic acid increased from $94.67-97 \%$ (Table 1) and this might be related to the inhibition of the synthesis of a large number of flagellin. In addition, the GH17 cells was filamentous during exponential growth phase (Fig. 5), however, the cells gradually became shorter as its propagation and returned to normal when it reached exponential phase. This phenomenon was clearly associated with the presence of autolysin which expressed by the gene lytA-lytF in Bacillus subtilis. It was worth noting that the sigD factor was necessary for lytA-lytF expression and the separation of the daughter cells formed by cell division requires the autolysin in the growth process (Mukherjee $S$ and Kearns DB 2014). However, in GH17 strain, the lytA-lytF genes could not be expressed because of the defect of SigD and thus the daughter cells cannot separate normally. Furthermore, the mechanism by which cell morphology returns to normal in the stationary phase may be related to the function of peptidoglycanase gene cwlO (Mitsui $\mathrm{N}$ et al. 2011). Our team will pay more attention to the dominant of morphological change in the future.

\section{Partial deletion of PBSX and its effects}

PBSX was resident as a prophage on the chromosome of $B$. subtilis 168, with a size of $28 \mathrm{~kb}$ (Krogh S et al. 1996). Some proteins encoded by genes from PBSX, such as XkdG, XkdK and XlyA were also detected in the fermentation broth of Bacillus subtilis (Tjalsma H et al. 2004; Yamane $\mathrm{K}$ et al. 2000). Therefore, it might be necessary to delete part of the $P B S X$ sequences to reduce the amount of extracellular proteins.

A total of $26.1 \mathrm{~kb} P B S X$ sequences from xkdB to xlyA gene were deleted from $\mathrm{GH} 17$ strain and the resultant strain $\mathrm{GH} 18$ was obtained. We found that the biomass of $\mathrm{GH} 18$ was always slightly lower than that of $\mathrm{GH} 17$ throughout the fermentation process(Fig. 2B) and the maximum biomass of GH18 was 1.37 $\mathrm{OD}$ lower than that of GH17. At the same time, the $\mathrm{Y}$-PGA yield of $\mathrm{GH} 18 / \mathrm{pHPG}$ also decreased slightly with a rate of $2.7 \%$ (Fig. 3B and Table 1). Those apparent changes could be attributed to the large-scale absence of $P B S X$, which reflected the complexity of the physiological relationship between the prophage and the host. However, it maked sense that the protein content in $\mathrm{Y}$-PGA extracted from fermentation broth of GH18/pHPG was $1.07 \%$, which was decreased by $13.7 \%$. On the whole, in order to reduce extracellular proteins and improve the purity of $y$-PGA product, $P B S X$ defect is necessary and its mild negative effects can be ignored.

\section{The extracellular proteins secreted by the GH18 strain}

In the $\mathrm{y}$-PGA extracted from fermentation broth of GH18/pHPG strain, about $1.0 \%$ of the proteins still remained. Therefore, the advanced high-resolution mass spectrometry was used to analyze the extracellular proteins of $\mathrm{GH} 18$ strain. As a result, a total of 449 kinds of proteins were identified in the protein extract. The abundance of each protein was characterized by the peak area of the mass spectrum, 
and the results showed that Yrpd was the most abundant protein. Then we used the peak area of Yrpd as a benchmark, and defined the ratio of the peak area of a protein to the peak area of Yrpd as the relative abundance of the protein. Finally, there were 60 proteins with a relative abundance of more than $0.2 \%$ (Supplementary Table 4). Among them, some proteins had a relative abundance of more than $3 \%$, which were Yxal, Ywof, YjdB, L-lactate dehydrogenase Ldh (EC:1.1.1.27) and YoqM. However, YjdB, Ldh and YoqM had never been isolated or identified by the 2D-PAGE (Tjalsma $\mathrm{H}$ et al. 2004; Yamane $\mathrm{K}$ et al. 2000). In addition, the order of protein spot size was Yxal>YrpD>Ywof in the previous 2D gel map, which was different from our observation. It was worth noting that the proteins whose encoding genes had been deleted in the strain GH18 such as Hag, FlgK, FliD, XkdG, XkdK and XlyA were not detected. This confirmed the validity of the previously performed gene knockout at the translation level.

From Table 3, a number of non-secretory proteins with high abundance were identified by mass spectrometry,such as L-lactate dehydrogenase (relative abundance 3.3\%), Acetolactate synthase (relative abundance 1.8\%) and Enolase (relative abundance 1.4\%). Those proteins, which were intracellular proteins involved in central carbon metabolism, had not been shown to exist in Bacillus subtilis fermentation broth. We assumed that they came from autolyzed cells or leaked from cells under the fermentation conditions.

\section{Defects of extracellular proteins YrpD, YwoF and YclQ}

Based on the results of mass spectrometry, the encoding genes of three unknown proteins YrpD, YwoF and YclQ were selected to be deleted in the GH18 strain and the resultant strain GH19 and GH19/pHPG were fermented, respectively. The results of fermentation showed that the biomass of GH19 strain was slightly higher than that of GH18 and was slightly lower than that of GH17 (Fig. 2B). Also, there was no any adverse effect on $\mathrm{Y}$-PGA yield and on the conversion rate of glucose and glutamic acid. (Table 1$)$. The protein content in $\mathrm{\gamma}$-PGA produced by the GH19/pHPG strain was $22.4 \%$ lower than that of GH18/pHPG. From the perspective of the relative abundance of proteins, the decrease of protein content in the $y-P G A$ product of GH19/pHPG was mainly attributed to the absence of YrpD and YwoF. As shown in Fig. 4, the SDS-PAGE results of extracellular proteins also support this conclusion that the bands of proteins around $17 \mathrm{kDa}$ and $58 \mathrm{kDa}$ almost disappeared. The size of these two protein bands was closed to the size of YrpD and YwoF, whose theoretical molecular mass was $24.9 \mathrm{kDa}$ and $51.4 \mathrm{kDa}$ respectively.

Obviously, the high resolution mass spectrometry provided us with precise and reliable data. It was expected that the purity of the $\mathrm{Y}$-PGA product will be further improved by further reducing the synthesis of extracellular proteins based on the reliable data.

\section{Deletion of the epsA-O operon and its effects}

Using phenol-sulfuric acid method, it was found that the $\mathrm{Y}$-PGA product contained $2.21 \%$ polysaccharides (Table 1) which were apparently originated from extracellular polysaccharides secreted by Bacillus 
subtilis. EPS was one of the major polysaccharides believed to be present extracellularly (Nagorska K et al. 2010), and it was the main component of the biofilm. In this study, the EPS coding gene epsA-O was knocked out to prevent the synthesis of such extracellular polysaccharides.

The $15 \mathrm{~kb}$ epsA-O operon was deleted in GH18 strain so that EPS-deficient strain GH21 and GH21/pHPG was obtained. Shake flask fermentation showed that the deletion of the epsA-O operon did not affect cells growth (data not shown). The polysaccharide content in Y-PGA product was reduced to $1.93 \%$ and the decrease rate was $11 \%$. At the same time, the $\gamma$-PGA yield of GH21/pHPG was unexpectedly reduced by $9.8 \%$ compared to that of GH18/pHPG (Table 1). Therefore, considering the deletion of epsA-O operon could not effectively reduce the content of polysaccharide in the $y$-PGA product and it would also bring down the $y$-PGA yield, it was not necessary to knock out the epsA-O operon from the $y$-PGA production strain.

In addition, the surface of the colony of GH21 still showed the characteristics of glossy and moist, and there was no difference with GH18 strain. This results were not identical to previous observation in the Bacillus amyloliquefaciens (Feng $\mathrm{J}$ et al. 2015) and it showed that in addition to EPS, Bacillus subtilis 168 secreted a considerable amount of other types of polysaccharides. Previous data had shown that B. subtilis could also secrete fructans with the medium contained sucrose (Dedonder R 1966). Since sucrose was not used as a carbon source in this study, the polysaccharide in they-PGA product was unlikely to be levan. Therefore, exploring the types of polysaccharides that exist extracellularly and affect the purity of $\mathrm{y}-\mathrm{PGA}$ is a problem worth studying in the future.

\section{Conclusion}

This study firstly exhibited a systematic modular gene engineering method for $\mathrm{Y}$-PGA purity improvement and we successfully reduced the extracellular protein secretion of Bacillus subtilis by $43.9 \%$, which significantly improved the purity of $\gamma$-PGA. This will greatly reduce the difficulty of $\gamma$-PGA purification and facilitate its application in the medical field. The defective strain constructed in this study is also suitable for the production of other valuable proteins with strict requirements on purity. Therefore, the strategy of constructing a cell factory with a simple background is of great significance on biosynthesis.

\section{Declarations}

\section{Acknowledgments}

The authors are grateful to the Beijing Proteome Research Center (BPRC) for providing technical support for mass spectrometry data analysis.

\section{References}


1. Ashiuchi M, Shimanouchi K, Nakamura H, Kamei T, Soda K, Park C, et al. (2004.) Enzymatic

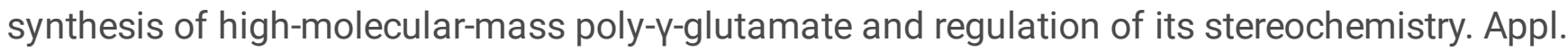
Environ. Microbiol. 70: 4249-4255.

2. Buescher JM, Margaritis A(2007) Microbial biosynthesis of polyglutamic acid biopolymer and applications in the biopharmaceutical, biomedical and food industries. Crit. Rev. Biotechnol. 27: 1-19.

3. Shih IL, Van YT (2001) The production of poly-(Y-glutamic acid) from microorganisms and its various applications. Bioresour. Technol. 79: 207-225.

4. Yu X, Wang M, Wang QH, Wang XM(2011) Biosynthesis of polyglutamic acid and its application on agriculture. Adv. Mater. Res. 183-185: 5.

5. Park SJ, Uyama H, Kwak MS, Sung MH (2019) Comparison of the stability of poly-y-glutamate hydrogels prepared by UV and y-ray irradiation. J. Microbiol. Biotechnol. 29: 1078-1082.

6. Min JH, Reedy LV, Charalampopoulos D, Kim YM, Wee YJ (2019) Optimized production of poly(Yglutamic acid) by bacillus sp. FBL-2 through response Ssurface methodology using central composite design. J. Microbiol. Biotechnol. 29: 1061-1070.

7. Goto A, Kunioka M (1992) Biosynthesis and hydrolysis of poly(Y-glutamic acid) from Bacillus subtilis IF03335. J. Agric. Chem. Socie. Japan. 56: 5.

8. Manocha B, Margaritis A (2010) A novel method for the selective recovery and purification of $\mathrm{Y}^{-}$ polyglutamic acid from Bacillus licheniformis fermentation broth. Biotechnol. Prog. 26: 734-742.

9. Kumar R, Pal P (2015) Fermentative production of poly ( $\mathrm{Y}$-glutamic acid) from renewable carbon source and downstream purification through a continuous membrane-integrated hybrid process. Bioresour. Technol. 177: 141-148.

10. Tjalsma H, Bolhuis A, Jongbloed JDH, Bron S, Van Dijl JM (2000) Signal peptide-dependent protein transport in Bacillus subtilis: a genome-based survey of the secretome. Microbiol. Mol. Biol. Rev. 64: 515-547.

11. Tjalsma H, Antelmann H, Jongbloed JD, Braun PG, Darmon E, Dorenbos R, et al. (2004) Proteomics of protein secretion by Bacillus subtilis: separating the "secrets" of the secretome. Microbiol. Mol. Biol. Rev. 68: 207-233.

12. Yamane K, Nakamura K, Kumano M, Shioda I, Sano K, Hirose I (2000) Proteome analysis of Bacillus subtilis extracellular proteins: a two-dimensional protein electrophoretic study. Microbiology. 146: 6575.

13. Nagorska K, Ostrowski A, Hinc K, Holland IB, Obuchowski M (2010) Importance of eps genes from Bacillus subtilis in biofilm formation and swarming. J Appl Genet. 51: 369-381.

14. Sutherland I (2001) Biofilm exopolysaccharides: a strong and sticky framework. Microbiology. 147: 3-9.

15. Marvasi M, Visscher PT, Martinez LC (2010) Exopolymeric substances (eps) from Bacillus subtilis: polymers and genes encoding their synthesis. FEMS. Microbiol. Lett. 313: 1-9. 
16. Guttenplan SB, Blair KM, Kearns DB (2010) The EpsE flagellar clutch is bifunctional and synergizes with EPS biosynthesis to promote Bacillus subtilis biofilm formation. PLoS Genet. 6: e1001243.

17. Liu S, Endo K, Ara K, Ozaki K, Ogasawara N (2008) Introduction of marker-free deletions in Bacillus subtilis using the arar repressor and the ara promoter. Microbiology . 154: 2562-2570.

18. Anagnostopoulos C, Spizizen J (1961) Requirements for transformation in Bacillus subtilis. J . Bacteriol. 81: 741-746.

19. Zhu H, Yang SM, Yuan ZM, Ban R (2015) Metabolic and genetic factors affecting the productivity of pyrimidine nucleoside in Bacillus subtilis. Microbial Cell Factories. 14: 54.

20. DuBois M, Gilles KA, Hamilton JK (1956) Colorimetric method for determination of sugars and related substances. Anal Chem. 28: 350-356.

21. Yu KH, Rustgi AK, Blair IA (2005) Characterization of proteins in human pancreatic cancer serum using differential gel electrophoresis and tandem mass spectrometry. J Proteome Res. 4: 1742-1751.

22. Estacio W, Anna-Arriola SS, Adedipe M, Márquez-Magaña LM (1998) Dual promoters are responsible for transcription initiation of the fla/che operon in Bacillus subtilis. J Bacteriol. 180: 3548-3555.

23. Mukherjee S, Kearns DB (2014) The structure and regulation of flagella in Bacillus subtilis. Annu. Rev. Genet. 48: 319-340.

24. Mitsui N, Murasawa H, Sekiguchi J (2011) Disruption of the cell wall lytic enzyme CwlO affects the amount and molecular size of poly-gamma-glutamic acid produced by Bacillus subtilis (natto). $\mathrm{J}$ Gen Appl Microbiol. 57: 35-43.

25. Krogh S, O"Reilly M, Nolan N, Devine KM (1996) The phage-like element PBSX and part of the skin element, which are resident at different locations on the Bacillus subtilis chromosome, are highly homologous. Microbiology. 142: 2031-2040.

26. Feng J, Gu Y, Quan Y, Cao M, Gao W, Zhang W, et al. (2015) Improved poly-Y-glutamic acid production in Bacillus amyloliquefaciens by modular pathway engineering. Metab. Eng. 32: 106-115.

27. Dedonder R (1966) Levansucrase from Bacillus subtilis. Method. Enzymol. 8: 500-505.

\section{Figures}

\section{Figure 1}

The process of strain construction

\section{Figure 2}


Effects of deleting genes on cell growth and $y$-PGA production. (A)Time profiles of cell growth and $y$-PGA production in recombinant strains. (B) Time profiles of cell growth and $\mathrm{Y}$-PGA production in recombinant strains. Values represent the means \pm SD of three independent experiments

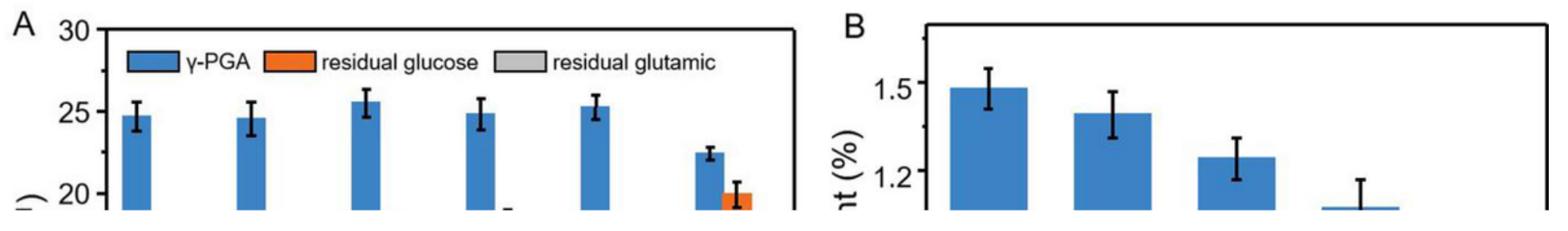

\section{Figure 3}

(A)Content of $Y$-PGA, residual glucose and residual glutamic in fermented broth of G423/pHPG and mutant strains cultured in shake flasks for $40 \mathrm{~h}$. (B)Content of protein impurity in $\mathrm{Y}$-PGA .Values represent the means $\pm S D$ of three independent experiments.

\section{Figure 4}

Gel for the extracellular proteins of starting strain G423 and mutant strains. Cells were cultured for $40 \mathrm{~h}$ in fermentation medium and the extracellular protein extract was separated by SDS-PAGE (15\% Tris-glycine SDS-PAGE gel). Lane M: protein standard, Lane 1:G423, Lane 2: GH16, Lane 3: GH18, Lane 4: GH19.

\section{Figure 5}

Cell morphology of strains G423,GH16 and GH17 (fla-che operon mutant) at different growth stages. White scale bar $=5 \mu \mathrm{m}$.

\section{Supplementary Files}

This is a list of supplementary files associated with this preprint. Click to download. 
- supportingfile.doc

Page 14/14 